\title{
Analysis of the Association Between Apolipoprotein E Polymorphism and Cardiovascular Risk Factors in an Elderly Population with Longevity
}

\author{
Carla Helena Augustin Schwanke, Ivana Beatrice Mânica da Cruz, Ney Furhmann Leal, \\ Rosane Scheibe, Yukio Moriguchi, Emílio Hideyuki Moriguchi \\ Porto Alegre, RS - Brazil
}

\begin{abstract}
Objective - To establish the allelic and genotypic frequencies related to apolipoprotein $E$ (ApoE) polymorphism and association of the genotypes with risk factors and cardiovascular morbidity in an elderly population with longevity.
\end{abstract}

Methods - We analyzed 70 elderly patients aged 80 years or more who were part of the Projeto Veranópolis. We used the gene amplification technique through the polymerase chain reaction-restriction fragment length polymorphism (PCR-RFLP) and cleavage with the restriction enzyme Hha I to identify the ApoE genotypes. The most frequent genotypes were compared considering biological variables and cardiovascular risks and morbidity.

Results - The frequencies of the E2, E3, and E4 alleles were $0.05,0.84$, and 0.11 , respectively, and of the genotypes were as follows: E3E3 (0.70), E3E4 (0.22), E2E3 (0.06), and E2E2 (0.02). Individuals with the E3E4 had a mean age greater than those with the E3E3. No association was observed between the genotypes and the variables analyzed, except for obesity, which was associated with the E3E3 genotype. Individuals with the E3E4 genotype had high levels of LDL-cholesterol and fibrinogen as compared with those with the E3E3 genotype.

Conclusion - The results suggest that the E4E4 genotypemaybeassociated withearlymortality. A balance between the protective or neutral factors and the cardiovascular risk factors may occur among the individuals with different genotypes, attenuating the negative effects of the E4 allele.

Keywords: apolipoprotein E, cardiovascular risk factors, elderly population with longevity

Faculdade de Medicina da Pontifícia Universidade Católica do Rio Grande do Sul Mailing address: Ivana Beatrice Mânica da Cruz - Instituto de Geriatria e Gerontologia da PUCRS - Av. Ipiranga, 6690 - 3º andar - 90610-000 Porto Alegre, RS, Brazil - E-mail: emoriguchi@pucrs.br English version by Stela Maris C. e Gandour
An increasing number of genetic polymorphisms has been associated with the susceptibility to cardiovascular diseases, such as the apolipoprotein E (ApoE) gene. Studies have shown that the $\mathrm{E} 4$ allelic variant is associated with the mechanisms of development of atherosclerosis, dementia, and, more recently, with the risk of bone fractures ${ }^{1-5}$.

The first genetic studies in cardiology was that of the association between ApoE polymorphism and coronary artery disease ${ }^{6}$. Apolipoprotein E participates in the metabolism of lipoproteins and plays a significant role in the transport of the cholesterol molecule [1- ligand of the LDL receptor; 2 - activator of enzymes like hepatic lipase; 3 - hepatic production of very low density lipoprotein(VLDL) $]^{7,8}$. In addition, this protein is related to immunoregulation and neurobiological routes (neuronal repair, remodeling, and protection). Apolipoprotein $\mathrm{E}$ is mainly synthesized in the liver (>90\%), but also in other tissues, such as the bowel, brain, lungs, kidneys, and macrophages, and secreted as a glycosylated protein. Apolipoprotein E polymorphism is located in the long arm of chromosome 19. Point changes are the molecular features of this polymorphism in the nitrogen bases, causing the replacement of 1 amino acid in the 112 and 158 positions of the peptide chain. The 3 most common isoforms are as follows: E2 (cysteine/cysteine), E3 (cysteine/arginine), and $\mathrm{E} 4$ (arginine/arginine). Of the 3 isoforms, E3 is the most frequently reported in the literature in the general population and $\mathrm{E} 4$ is rare in the centenarian population. The allelic frequency of ApoE varies in the populations because the polymorphism of its locus ranges from $16 \%$ to $53 \%$ according to the population. Therefore, different phenotypes of ApoE exist, and they result from 6 genotypes as follows: 3 homozygous (E2E2, E3E3, and E4E4), and 3 heterozygous (E2E3, E3E4, and E2E4). Apolipoprotein E polymorphism changes protein both in its structure and function. The $\mathrm{E} 2$ isoform generates a protein whose binding to the LDL receptor is defective (in the rare situation of ho- 
mozygosis and in the presence of other factors, such as diabetes mellitus, it may generate the type III Fredrickson dyslipidemia or dysbetalipoproteinemia). On the other hand, the $\mathrm{E} 4$ isoform generates a protein whose affinity for the LDL receptor is 4 times greater than that for LDL itself ${ }^{1-5,9}$. Population studies have shown that the serum levels of LDL-cholesterol (LDL-c) and apolipoprotein $\mathrm{B}(\mathrm{ApoB})$ are higher in individuals with the $\mathrm{E} 4$ allele, intermediate in individuals with the E3 allele, and lower in individuals with the E2 allele ${ }^{10,11}$.

A few studies have also associated the presence of the E2 allele with greater longevity, because a higher frequency of that allele is observed in nonagenarians and centenarians ${ }^{12,13}$. These results, however, have not been reproduced in all the populations studied, and they seem not to follow a universal pattern. Excluding the possible methodological problems associated with this type of study reviewed by Marian ${ }^{5}$ and Mansur ${ }^{6}$, one of the hypotheses to be considered is that in chronic and degenerative diseases with a multifactorial origin, the set of genetic variations of a population associated with the social and environmental surroundings of the same population and with the processes related to biogerontology (biology of aging) can be responsible for the varied results, which have been found so far. Therefore, additional investigations about the impact of certain genetic polymorphisms, about the traditional risk factors for the development of cardiovascular diseases, and especially the coronary arteries and aging are required in individuals with longevity ( $>80$ years).

The relevance of this type of study is based on the fact that the phenomenon of population aging will markedly increase the number of elderly individuals older than 80 years, who constitute a group especially susceptible to cardiovascular events. However, recent studies, including the Framingham Study, have shown that the traditional risk factors of cardiovascular diseases do not apply with the same intensity observed in younger age groups ${ }^{14,15}$. Therefore, we need to determine which risk factors really influence the susceptibility to cardiovascular diseases in this population group.

Based on these considerations, we analyzed the association between different ApoE genotypes, cardiovascular risk factors, and morbidity in the elderly individuals aged 80 years or older living in the municipality of Veranópolis, in the State of Rio Grande do Sul, and who took part in the Projeto Veranópolis. That project analyzed the interaction of genetic and environmental variables related to successful aging and to cardiovascular diseases. The basic demographic and epidemiologic profile of the municipality of Veranópolis is shown in table $\mathrm{I}^{16}$.

\section{Methods}

We carried out a cross-sectional, individual, observational, analytical study ${ }^{17}$ on 64 elderly individuals aged 80 years or more, who were chosen according to criteria of representativity and randomization in a total population of 220

\begin{tabular}{|c|c|c|c|}
\hline \multicolumn{4}{|c|}{$\begin{array}{l}\text { Table I - Comparison of the demographic and epidemiological } \\
\text { data of the municipality of Veranópolis, of the state of Rio Grande } \\
\text { do Sul (RS), and of Brazil, in the period from } 1996 \text { to } 1997^{16}\end{array}$} \\
\hline Variables & Veranópolis & RS & Brazil \\
\hline ELife expectancy at birth & 77.7 & 71.8 & 67.7 \\
\hline Coefficient of infant mortality & $1 / 1.000$ & $17.5 / 1.000$ & $26.4 / 1.000$ \\
\hline Mortality due to cardiovascular diseases & 29 & 34 & 27 \\
\hline Mortality due to infectious diseases & 0.7 & 1.7 & 2.8 \\
\hline
\end{tabular}

individuals of Italian heritage within that age bracket living in the municipality of Veranópolis in 1998.

Apolipoprotein E genotyping and complementary biochemical examinations were as follow: blood samples of a peripheral vein were withdrawn according to the venoclysis system with a disposable vacuum device (Vacutainer) and stored in tubes with $0.1 \%$ EDTA (final volume at the concentration of $1 \mathrm{mg} / \mathrm{dL}$ ). After that, the material collected was maintained at $4^{\circ} \mathrm{C}$ until DNA extraction for up to 24 hours. DNA extraction was performed according to the technique reported by Debomoy ${ }^{18}$. The general protocol of extraction comprised the following steps: 1) the blood samples collected were centrifuged at 5,000 rpm for 5 minutes; 2 ) after centrifugation, the region containing the leukocytes was transferred to tubes of $1.5 \mathrm{~mL}$ and washed with PBS (phosphate buffered saline, $\mathrm{pH}$ 7.5); 3) for extracting DNA from the leukocytes (in $200 \mu \mathrm{LPBS}$ ), $100 \mu \mathrm{L}$ of the lysis buffer $(10 \mathrm{mM}$ Tris, $100 \mathrm{mMEDTA}, 0.5 \% \mathrm{SDS}, 200 \mu \mathrm{g} / \mathrm{mL}$ proteinase $\mathrm{K}$ ), $2.5 \% \mathrm{SDS}$, and $25 \mathrm{mMEDTA} \mathrm{pH} 8.0$ were added, and that was followed by incubation at $55^{\circ} \mathrm{C}$ for 3 hours; 4 ) after incubation, the DNA of the sample was extracted by 2 washes with a solution of phenol, chloroform, and isoamyl alcohol (25:24:1); 5) the DNA present in the aqueous portion was then precipitated by adding 0.1 volume of sodium acetate and 0.7 volume of isopropanol and incubated at $-20^{\circ} \mathrm{C}$; 6) the DNA, observed as a clear and gelatinous sediment, was dissolved in $50 \mu \mathrm{L}$ of Milli-Q water and maintained at $20^{\circ} \mathrm{C}$ for later use in the reaction of gene amplification called polymerase chain reaction (PCR).

Polymerase chain reaction was performed according to the method reported by James et al ${ }^{19}$ using the primers apo EF 5'-TAA GCTTGGCACGGC TGTCCAAGGA-3' (25-mer) andapoER 5'-ACAGAATTCGCCCCGGCCTGGTACAC$3^{\prime}$ (26-mer). The mixture of the reaction (total of $50 \mu \mathrm{L}$ ) was prepared with $10 \mathrm{pmol}$ of each primer, $100 \mu \mathrm{MdNTPs}$, $1 \mathrm{U}$ of Taq Polymerase (CenBiot-RS), buffer containing $1.5 \mathrm{mM}$ $\mathrm{MgCl}_{2}, 1 \% \mathrm{DMSO}$, and $2 \mathrm{mmL}$ of the DNA of the sample.

The amplification process consisted of an initial denaturation at $95^{\circ} \mathrm{C}$ for 5 minutes, followed by 30 cycles of denaturation at $95^{\circ} \mathrm{C}$ for 1 minute, coiling at $61^{\circ} \mathrm{C}$ for 1 minute, extension at $70^{\circ} \mathrm{C}$ for 1 minute, and a final extension at $72^{\circ} \mathrm{C}$ for 10 minutes.

The efficacy of PCR was visualized through electrophoresis in agarose gel $(2 \%)$ with ethidium bromide, when a band of 240 base pairs (bp) was observed under ultraviolet light.

Genotyping was performed by digesting the PCR pro$\operatorname{duct}(20 \mu \mathrm{L})$ with $5 \mathrm{U}$ of the restriction enzyme Hha I (Gibco) 
in a specific buffer. The solution undergoing digestion was incubated at $37^{\circ} \mathrm{C}$ for 3 hours, and then analyzed in polyacrylamide gel (15\%) using a molecular weight marker of 10bp ladder. The characteristic bands of each allele were then analyzed and identified.

For biochemical assessment, samples of venous blood were collected after study participants had fasted for 12 hours. The venoclysis system with the disposable vacuum device (Vacutainer) was used. Blood was collected in tubes with no anticoagulant to quantify the lipid profile, Lp(a), glucose, and uric acid. For fibrinogen quantification, blood was collected in tubes with sodium citrate. The blood samples were centrifuged for 15 minutes in a Kubota KC-70 centrifuge (Japan) at the velocity of 3,000 rpm to separate plasma from the remaining cells. Plasma was then divided into five 1.0-mL aliquots in Eppendorf tubes with micropipettes. The plasma aliquots were then refrigerated between -8 and $4^{\circ} \mathrm{C}$ for a maximum of 24 hours ${ }^{20}$.

To analyze total cholesterol, the manual technique of the enzymatic colorimetric reaction was used with the commercial enzymatic reagent Cholesterin/Cholesterol ChodPap(MPR2, Boehringer-Mannheim, Germany). Readings of standard cholesterol levels of $50 \mathrm{mg} / \mathrm{dL}, 100 \mathrm{mg} / \mathrm{dL}, 200 \mathrm{mg} /$ $\mathrm{dL}$, and $400 \mathrm{mg} / \mathrm{dL}$ were performed with the Preciset Cholesterol Calibrator 125512 (Boehringer-Mannheim, Germany), and the final value was the mean of the 2 measurements performed for each plasma sample ${ }^{20}$. To analyze HDL-cholesterol (HDL-c), the heparin- $\mathrm{Mn}^{2+}$ precipitation method by Gildez was used with some adaptations. The lipoproteins containing apolipoproteins B-100 (VLDL and LDL) were precipitated according to the heparin- $\mathrm{Mn}^{2+}$ precipitation method (Sigma Chemical Co, USA) and then incubated and centrifuged (refrigerated centrifuge, RB-1811 Model, Tomy Seiko Co. Ltd, Japan). The floating material was then collected for quantification of HDL-c particles through the colorimetric enzymatic reaction for cholesterol; the mean of 2 measurements for each plasma sample was considered the final value ${ }^{20}$. The LDL-c value was obtained with the Friedewald formula for triglyceride levels below $400 \mathrm{mg} / \mathrm{dL}$. Samples with triglyceride levels above $400 \mathrm{mg} / \mathrm{dL}$ were excluded ${ }^{21}$.

The manual technique of colorimetric enzymatic reaction was used for triglyceride quantification with the commercial enzymatic kit Labtest TG Gpo-Ana (Argentina). Readings of standard triglyceride levels of $150 \mathrm{mg} / \mathrm{dL}$ and $300 \mathrm{mg} / \mathrm{dL}$ were performed with the Preciset Trigliceride Calibrator 125512 (Boehringer-Mannheim, Germany), and the final value was the mean of the 2 measurements performed for each plasma sample ${ }^{20}$. Levels above $200 \mathrm{mg} / \mathrm{dL}$ were considered increased. Table II shows the reference values of total cholesterol, LDL-c, HDL-c, and triglycerides ${ }^{21}$.

Lipoprotein(a) levels were obtained with the Boehringer nephelometric system (Boehringer Nephelometer 100); the kit of $\mathrm{N}$ antiserum against human apolipoprotein(a) and the kit of N Latex Lp(a) reagent were used. Lipoprotein(a) levels above $30 \mathrm{mg} / \mathrm{dL}$ were considered increased ${ }^{20}$. For glucose level determination, the colorimetric enzymatic method was performed using the Bio Diagnóstica ICQ Ltda

\begin{tabular}{|c|c|c|c|}
\hline \multicolumn{4}{|c|}{$\begin{array}{l}\text { Table II - Reference values of total cholesterol (TC), LDL-c, HDL- } \\
\text { c, and triglycerides (TG) for adults }\left(>20 \text { years) }{ }^{19}\right.\end{array}$} \\
\hline \multirow[t]{2}{*}{ Lipids } & \multicolumn{3}{|c|}{ Values (md/dL) } \\
\hline & Desirable & Borderline & Alterated \\
\hline $\mathrm{TC}$ & $<200$ & $200-239$ & $\geq 240$ \\
\hline LDL-c & $<130$ & $130-159$ & $\geq 160$ \\
\hline HDL-c & $\geq 35$ & - & \\
\hline TG & $<200$ & - & $\geq 200$ \\
\hline
\end{tabular}

commercial kit (Paraná, Brazil), and the mean of 2 measurements performed for each plasma sample was considered the final value ${ }^{20}$. Glycemic levels above $126 \mathrm{mg} / \mathrm{dL}$ were considered increased. Plasma fibrinogen was quantified according to the turbidimetric method using the Tecnow 7000 spectrophotometer (Tecnow Instrumentos Científicos, São Paulo). Fibrinogen levels above $300 \mathrm{mg} / \mathrm{dL}$ were considered increased. Measurement of plasma uric acid was performed using the enzymatic method (UV, Method GIDH) with the Merck commercial kit (Germany). Levels above 7.0 $\mathrm{mg} / \mathrm{dL}$ were considered increased ${ }^{22}$.

In addition, complementary clinical examinations were performed and structured interviews were applied to detect cardiovascular risk and morbidity.

The following 3 clinical parameters were used for obesity: body mass index, waist/hip ratio, and percent body fat (\% fat). Considering that none of those parameters alone can efficiently indicate levels of obesity, individuals who were classified as obese in the 3 parameters were considered obese, as were those classified as obese in at least 2 parameters and overweight as established according to the body mass index. Body mass index was obtained with quantification of weight (kilograms) and height (meters) with a mechanical scale (Filizolla, São Paulo). Then, the body mass index was calculated by dividing the weight in kilograms by the square of the height in meters squared $\left(\mathrm{kg} / \mathrm{m}^{2}\right)$. The waist/hip ratio was obtained by measuring the minimum abdominal circumference (measured in meters at the level of the iliac crest) and the maximum abdominal circumference (measured in meters at the level of the greater trochanter). Then, the waist/hip ratio was calculated by dividing the minimum abdominal circumference by the maximum abdominal circumference. Percent fat was obtained with fat quantification by electrical bioimpedanciometry. For this quantification, the elderly had to be in the supine position. According to the body mass index (BMI) classification, individuals whose BMI was $\geq 30$ were considered obese, and those whose BMI was between 25 and 30 were considered overweight, for both sexes. According to the waist/hip ratio, females whose waist/hip ratio was above $0.8 \mathrm{~cm}$ were considered obese, as were males whose waist/hip ratio was above $1.0 \mathrm{~cm}$. In regard to \% fat, individuals of both sexes whose fat measured above $30 \%$ were classified as obese ${ }^{23}$.

In regard to systemic arterial hypertension assessment and classification, the criterion of the III Consenso 
Brasileiro para o Tratamento da Hipertensão Arterial of 1998 was used. According to that criterion, individuals whose systolic blood pressure levels were $>140 \mathrm{mmHg}$ or diastolic blood pressure levels were $>90 \mathrm{mmHg}$, or both, were considered hypertensive. The classification of the elderly as hypertensive required alteration in at least 2 of the 3 following parameters investigated: increased systolic or diastolic blood pressures, or both; report of hypertension diagnosed by a physician; use of antihypertensive medication. Blood pressures were measured with a mercury sphygmomanometer (Erka, Germany) with an adequate cuff for the right arm circumference. Each participant remained at rest (sitting) for at least 5 minutes prior to the measurements. Two measurements were taken with an interval of approximately 30 minutes between them. The appearance of the heart sounds was used to identify the systolic blood pressure and its disappearance (Korotkoff phase V) to identify the diastolic blood pressure ${ }^{24}$. Due to the possibility of pseudohypertension caused by stiffening of the brachial artery by atherosclerosis, which may increase blood pressure by $30 \mathrm{~m}$ $\mathrm{mHg}$ or more, the Osler maneuver was used concomitantly with systolic blood pressure measurement. The Osler maneuver is considered positive when the cuff is inflated above the systolic blood pressure level and the radial artery remains palpable ${ }^{22}$. The cases, in which that happened, were excluded from the study ${ }^{25}$.

Diabetes mellitus was defined when at least 1 of the following situations happened: the patient reported a previous diagnosis by a physician; the patient was using a medication (oral antidiabetic drugs or insulin, or both); when fasting glycemia was $>126 \mathrm{mg} / \mathrm{dL}^{26}$.

Morbidity due to cardiovascular diseases was defined by the presence of a previous personal history or diagnosis of angina or intermittent claudication or stroke, as described below: 1) thoracic pain of the anginal type or intermittent claudication, characterized by the presence of thoracic pain of the anginal type and intermittent claudication defined by the report of such symptoms, according to Rose's protocol; 2) stroke. The presence of ischemic stroke and acute myocardial infarction was defined by the report of such pathological situations and complementary neurological and cardiological examinations ${ }^{27}$.

The variables of cardiovascular risk related to lifestyle were physical activity, alcohol ingestion, and smoking.

The physical activity was measured by calculating energy expenditure in kilocalories per week ( $\mathrm{kcal} /$ week) for different activities using the intensity code of either Taylor et al or McArdle et al, or both, as an index of specific energy expenditiure in $\mathrm{kcal} / \mathrm{min}$ for different physical activities. For classifying physical activity, we used the cut point of 3,000 $\mathrm{kcal} /$ week proposed by Paffenbarger, which was considered a physical activity level favorable to cardiovascular protection of middle-aged individuals ${ }^{27,28}$.

Ingestion of alcoholic beverages was assessed through the report of the amount of alcohol ingested per week. This amount was calculated in grams per week using the correc- tion factors for the mean alcohol content according to standard measures for wine, beer, and hard liquor (standard drink) adapted from suggestions of the Serviço de Atenção ao Alcoolismo e Drogadição do Ministério da Saúde ${ }^{16}$. According to these suggestions, the alcoholic content of wine was estimated at $11 \%$ with $140 \mathrm{~mL}$ ( 1 glass) as a standard measure; the alcoholic content of beer was estimated at $4 \%$ with $350 \mathrm{~mL}$ ( 1 or 2 cans of beer equivalent to 1 bottle) as a standard measure; and the alcoholic content of the hard liquor was estimated at $45 \%$ with $35 \mathrm{~mL}$ (equivalent to 1 drink) as a standard measure ${ }^{27}$.

Smoking was assessed through the report of using or not using tobacco (cigarettes and other forms). Two groups were considered: 1) nonsmokers - individuals who never smoked or who stopped smoking at least 2 years before the interview date, and who never resumed smoking; 2) current smokers or smokers - individuals who smoked at least 1 cigarette/day or who quit smoking less than 2 years before.

Statistical analysis was performed using version 9.0 of the statistical software SPSS, $1999^{29}$. After the molecular diagnosis of the sample, the gene (or allele) and genotypic frequencies were calculated with the Hardy-Weinberg law ${ }^{30}$. The genotypic frequencies were calculated with the equation $\mathrm{p}^{2}+\mathrm{q}^{2}+\mathrm{r}^{2}+2 \mathrm{pq}+2 \mathrm{pr}+2 \mathrm{qr}=1$, in which $\mathrm{p}=$ allele 3 (the most frequent allele in the human populations studied up to that point), $\mathrm{q}=$ allele $\mathrm{e} 4$, and $\mathrm{r}=$ allele $\mathrm{e} 2$. The gene frequencies were calculated with the equation: $p+q+r=1$, and they were tested for the Hardy-Weinberg equilibrium with the chisquare test of the observed and expected frequencies for each allele (the chi-square goodness-of-fit test).

The following statistical analyses were performed to assess the association between the most frequent genotypes in the sample studied and the variables analyzed in the study: 1) test of association between categorical variables: the univariate nonparametric chi-square test for independent samples. In the cases in which the expected frequency was lower than 5 in a $2 \times 2$ table, the Fisher exact test was used. In both cases, two-tailed tests were used, because, being more conservative, spurious significances could be avoided;2) multivariate analysis was performed with logistic regression. All variables with univariate statistical significance $(p=0.1)$ were included in the test. To assess the interaction of the variables associated with the genotypes or the independent association of variables, each variable was excluded from the analysis. In case of significant loss $(p=0.05)$ of a variable when another was excluded from the analysis, the association between them was considered; 3 ) comparison of continuous variables between the genotypes: the 1-way ANOVA or multifactorial ANOVA was used, followed by the Student $t$ test or the Mann-Whitney test.

This study was approved by the Scientific Committee of the Medical School of the Pontifícia Universidade Católica do Rio Grande do Sul (PUC-RS) and by the Committee on Ethics and Research of the PUC-RS, and was referred to the National Committee on Ethics and Research of the National Health Committee of the Ministry of Health, because it belonged to the area of genetics. All volunteers or a re- 
lative were required to sign the formal consent, and when this was not possible, the volunteer's verbal consent was required.

\section{Results}

Of the six possible ApoE genotypes, only four were observed in the population studied: E3E3 (70\%), E3E4 (22\%), E2E3 (6\%), and E2E2 (2\%). The gene and genotypic frequencies are shown in table III. As the sample size of the E2E2 and E2E3 genotypes was very low (1 genotyped individual and 4 genotyped individuals, respectively), their descriptive statistics were included in the results presented, even though they were not included in the comparative statistical analyses of the most frequent genotypes (E3E3 andE3E4).

Even though the frequencies were within the HardyWeinberg equilibrium $\left(x^{2}=0.97\right.$; degree of freedom $=1 ; p>$ $0.57)$, the frequency of the E4 allele in the population studied was above $10 \%$.

Table IV shows the mean values observed for the biological variables analyzed in the study. Among the individuals with the most frequent genotypes, E3E3 and E3E4, significant differences were observed in regard to age, body mass index, and diastolic blood pressure. Individuals with the E3E4 genotype were significantly older than those with the E3E3 genotype. Even though the other genotypes were not included in the statistical analysis, the age of the E2E2 genotype individual was closer to the mean age of the E3E3 genotype individuals, while the mean age of the E2E3 individuals tended to be similar to that observed in the E3E4 genotype individuals.

In regard to body mass index, the E3E3 individuals, on average, tended to be overweight, while both the E3E4 and E2E3 individuals had a mean body mass index within the normal range. Unlike this pattern, the E2E2 individual had a body mass index below normal, which was considered to result from undernourishment.

Surprisingly, the E3E4 genotype individuals were the only ones to have a diastolic blood pressure considered within the normal range.

\begin{tabular}{|c|c|c|c|}
\hline \multicolumn{4}{|c|}{$\begin{array}{l}\text { Table III - Gene and genotypic frequencies of the apolipoprotein } \\
\text { E (Apo E) gene in the elderly population above the age of } 80 \text { years } \\
\text { in Veranópolis, in the state of Rio Grande do Sul }\end{array}$} \\
\hline Gene & & $\mathrm{n}$ & Frequency \\
\hline \multirow[t]{11}{*}{ Apo E } & Gene (Allele) & & \\
\hline & E2 & & 0.05 \\
\hline & E3 & & 0.84 \\
\hline & E4 & & 0.11 \\
\hline & Genotypic & & \\
\hline & E2E2 & 1 & 0.02 \\
\hline & E2E3 & 4 & 0.06 \\
\hline & E2E4 & 0 & 0 \\
\hline & E3E3 & 45 & 0.70 \\
\hline & E3E4 & 14 & 0.22 \\
\hline & E4E4 & 0 & 0 \\
\hline
\end{tabular}

A total of eight biochemical variables directly or indirectly related to cardiovascular risk were compared among the genotypes (tabs. V and VI).

Of these variables, three had significantly different means among the elderly with different genetic ApoE polymorphisms: LDL-c, uric acid, and fibrinogen. Both E3E3 and E3E4 individuals had mean LDL-c levels above the expected. The E3E4 elderly had a mean LDL-c concentration significantly higher than E3E3 individuals did. Individuals with the remaining genotypes tended to have LDL-c values within the expected range.

On the contrary, E3E3 individuals had a mean uric acid concentration significantly higher than E3E4 individuals. However, all individuals had their means within the expected values.

Even though the fibrinogen levels were statistically higher in E3E4 individuals, all means observed in the remaining genotypes were not considered indicative of cardiovascular risk.

In a multivariate analysis with a logistic regression model, a significant association was observed between the LDL-c (130 mg/dL), uric acid (6 mg/dL), fibrinogen $(300 \mathrm{mg} /$ $\mathrm{dL})$, and cholesterol $(220 \mathrm{mg} / \mathrm{dL})$ levels and the genotypes. However, it is worth noting that only cholesterol had a significance level between 0.05 and 0.1 . The remaining variables had a more consistent statistical relation with significance levels ranging from 0.00 to 0.04 .

The analysis of the values obtained in calculating the odds ratio showed that individuals with the E3E4 genotype were twice more likely to have LDL-c and fibrinogen levels above that expected than individuals with the E3E3 genotype were. On the other hand, E3E4 individuals were less likely to have more elevated uric acid levels than E3E3 individuals were.

Lifestyle variables, such as smoking and physical acti-

\begin{tabular}{|c|c|c|c|}
\hline \multicolumn{4}{|c|}{$\begin{array}{l}\text { Table IV - Comparison of the biological profile, cardiovascular } \\
\text { risks, and lifestyle of the elderly according to the ApoE genotypes }\end{array}$} \\
\hline & $\begin{array}{c}\mathrm{E} 3 \mathrm{E} 3 \\
\mathrm{Mean} \pm \mathrm{SD}\end{array}$ & $\begin{array}{c}\mathrm{E} 3 \mathrm{E} 4 \\
\mathrm{Mean} \pm \mathrm{SD}\end{array}$ & $p$ \\
\hline Age & $82.72 \pm 3.1$ & $85.36 \pm 3.23$ & 0.008 \\
\hline Total cholestero & $204.99 \pm 39.28$ & $224.91 \pm 55.32$ & 0.14 \\
\hline LDL-c & $133.2 \pm 32.8$ & $155.56 \pm 47.26$ & 0.05 \\
\hline HDL-c & $46.7 \pm 12.72$ & $44.8 \pm 10.43$ & 0,61 \\
\hline Triglycerides & $136.69 \pm 81.29$ & $122.64 \pm 49.57$ & 0.54 \\
\hline Uric acid & $5.82 \pm 0.92$ & $4.91 \pm 0.59$ & 0.005 \\
\hline Fibrinogen & $194.97 \pm 63.99$ & $243.72 \pm 60.38$ & 0.04 \\
\hline $\mathrm{Lp}(\mathrm{a}))$ & $30.26 \pm 27.86$ & $29.15 \pm 28.32$ & 0.91 \\
\hline BMI & $27.44 \pm 5.14$ & $23.67 \pm 3.5$ & 0.02 \\
\hline Fat & $37.33 \pm 6.41$ & $33.92 \pm 5.68$ & 0.14 \\
\hline Waist/hip ratio & $0.91 \pm 0.008$ & $0.86 \pm 0.006$ & 0.09 \\
\hline SBP & $16.78 \pm 25$ & $151.72 \pm 28.27$ & 0.2 \\
\hline DBP & $88.77 \pm 12.95$ & $80.07 \pm 13.46$ & 0.033 \\
\hline Physical activity & $6406.9 \pm 5872.2$ & $4399 \pm 2006.2$ & 0.32 \\
\hline Alcohol consumption & $178.96 \pm 165.1$ & $82.1 \pm 111.61$ & 0.2 \\
\hline \multicolumn{4}{|c|}{$\begin{array}{l}\text { Units of the variables analyzed: age (years); physical activity (kcal/week); } \\
\text { alcohol consumption ( } \mathrm{g} / \text { week); systolic blood pressure (SBP, mmHg); } \\
\text { diastolic blood pressure (DBP, mmHg); BMI - body mass index; fat }(\%) \text {; } \\
\text { SD - standard deviation; } p \text { - significance level obtained with the Student } \\
t \text { test. The statistical comparison was performed only between the E3E3 } \\
\text { and E3E4 genotypes. }\end{array}$} \\
\hline
\end{tabular}




\begin{tabular}{|lccc|}
\hline \multicolumn{2}{|c|}{ Table $\mathbf{V}$ - Comparison of the biochemical variables related to the metabolism of the lipoproteins and cardiovascular risk among the different } \\
ApoE genotypes
\end{tabular}

vity, were similar for the genotypes analyzed (tab. IV). In regard to smoking, less than $3 \%$ of the population studied smoked. No specific genotype association was observed $\left(x^{2}=0.75\right.$, degree of freedom $\left.=1, p=0.77\right)$.

The last analysis of the study involved the assessment of the association between risk factors and cardiovascular morbidity and the most frequent ApoE genotypes. Due to the low frequency of cardiovascular morbidity in the population studied, those frequencies were grouped (stroke, acute myocardial infarction, intermittent claudication, and angina pectoris) to enable the statistical analysis.

The group of elderly with the E3E3 genotype tended to have a higher number of individuals affected by cardiovascular events, obesity, and hypertension; however, only obesity was statistically significant in the genotypes studied. More E3E3 individuals were obese than were E3E4 individuals.

E3E4 elderly individuals tended more to familial morbidity and mortality due to cardiovascular diseases, diabetes mellitus, and dyslipidemia. However, these differences were not statistically significant (fig. 1).

\section{Discussion}

The analysis of the results suggests the existence of a more complex interaction between ApoE polymorphism and the variables related to the cardiovascular events studied. Genotype-dependent relations, which have not yet been explored, may exist.

In regard to the gene and genotypic frequencies related to ApoE polymorphism, it is important to emphasize that these frequencies vary according to the population studied. Review studies have shown that the gene frequencies related to this polymorphism are extremely variable, mainly in regard to the $\mathrm{E} 4$ allele frequency ${ }^{1,2}$. In Europe, this gene has a gradient distribution, the $\mathrm{E} 4$ allele being more frequent in the northern region and less frequent in the southern region. In Asian populations, this allele has a low frequency, unlike that of the African and New Guinea populations ${ }^{31-33}$. However, specific studies on the possible causes of this variation are still in their infancy.

In general, the gene frequencies observed in the present study were similar to those reported by other authors.
The E3E3 genotype has been the most frequent (55\%) in the populations studied so far, followed by the E3E4 genotype $(26 \%)^{3,31}$. The results obtained were also similar to those of the northern region of Italy ${ }^{33}$. Data on the Italian immigration to Veranópolis point to a greater number of individuals coming from northern Italy; thus, this similarity was expected. To demonstrate this, table VII compares ApoE frequencies in different populations or different age groups of these populations, or both ${ }^{3,4,10,31,33,34}$. Unfortunately, data on the ApoE frequencies of the Brazilian population are still lacking, which hinders the comparison with the frequencies obtained in the present study. In general, the greater frequency of individuals with the E3E4 genotype in Veranopolis as compared with that of the Italian populations is notable. Further genetic studies may help to elucidate this phenomenon.

Despite the high frequency of the E4 allele in the elderly, no E4E4 genotype was observed. Several studies carried out in other countries suggest the occurrence of a frequency-dependent effect of the E4 allele, ie, the presence of 2 copies of the E4 allele is associated with early mortality. As no elderly individual with this genotype was observed, the data obtained confirm this hypothesis.

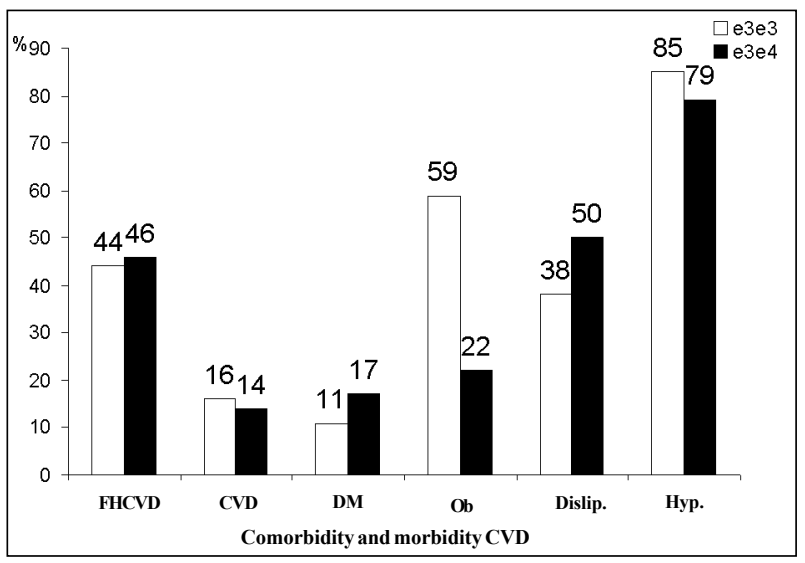

Fig. 1 - Comparison of risks for cardiovascular diseases, associated comorbidity, and morbidity. FHCVD - familial history for cardiovascular diseases; CVD - sum of the cardiovascular diseases observed in the sample investigated (stroke, acute myocardial infarction, intermittent claudication, and angina pectoris), DM - diabetes mellitus; Ob - obesity; Dislip - dyslipidemia; Hyp - hypertension. 


\begin{tabular}{|lccccc|}
\hline $\begin{array}{c}\text { Table VI - Relation between the ApoE genotypes of the elderly } \\
\text { individuals and variables of the lipid profile assessed by simple } \\
\text { logistic regression and their respective odds ratio }\end{array}$ \\
\hline Variables & $X^{2}$ & $P$ & Odds ratio & $95 \% \mathrm{CI}$ \\
\hline LDL-cholesterol $(130 \mathrm{mg} / \mathrm{dL})$ & 5.82 & 0.013 & 2.61 & $1.04-6.56$ \\
Uric acid $(6 \mathrm{mg} / \mathrm{dL})$ & 6.05 & 0.007 & 0.09 & $0.10-0.78$ \\
Fibrinogen $(300 \mathrm{mg} / \mathrm{dL})$ & 12.21 & 0.042 & 2.07 & $1.20-7.88$ \\
Total cholesterol $(240 \mathrm{mg} / \mathrm{dL})$ & 3.58 & 0.060 & 1.23 & $2.77-5.43$ \\
\hline \multicolumn{2}{|l}{$X^{2}$ - chi-square; $\mathrm{CI}$ - confidence interval } \\
\end{tabular}

Surprisingly, however, in our results, individuals with the E3E4 genotype had a significantly higher mean age than E3E3 individuals did. Differences in the ApoE frequencies and longevity strongly suggest that the relations between certain genotypes and longevity are also influenced by other variables, such as environmental factors and the interaction with other genetic factors. This variation could be responsible for the difficulty in defining a biological and clinical profile strongly correlated with the risk factors for cardiovascular diseases at advanced ages ( $>80$ years). Therefore, we believe that this may have contributed to the result obtained.

Of the several biological variables studied, body mass index and diastolic blood pressure showed significant differences among the most frequent ApoE genotypes. In this case, individuals with the E3E3 genotype had a mean body mass index classified as overweight and a greater diastolic blood pressure. No consistent data allowing a comparison or inference about such findings were found in previously published studies. As this characteristic is usually associated with an increase in the risk of chronic and degenerative diseases, would this characteristic have a negative effect in the E3E3 genotype? This question requires better investigation, as does the possibility of a causal or potential relation between body mass index and the ApoE genotypes. We should not overlook the possibility that this finding may have occurred by chance, or may have been determined by the small size of the sample.

\begin{tabular}{|c|c|c|c|c|}
\hline \multicolumn{5}{|c|}{$\begin{array}{l}\text { Table VII - Comparison of the genetic frequencies of ApoE in } \\
\text { different populations }\end{array}$} \\
\hline Frequencies & $\begin{array}{c}\text { Italians } \\
\text { Veranópolis } \\
\text { RS }\end{array}$ & $\begin{array}{l}\text { Populations } \\
\text { Italians }^{32} \\
\text { Central } \\
\text { Italy }\end{array}$ & $\begin{array}{c}\text { Italians }{ }^{33} \\
\text { Northern } \\
\text { Italy }\end{array}$ & $\begin{array}{r}\text { British }{ }^{31} \\
\text { Cambridge }\end{array}$ \\
\hline \multicolumn{5}{|l|}{ Genotypic } \\
\hline E2/2 & 0.02 & 0.013 & 0.016 & 0.008 \\
\hline E3/2 & 0.06 & 0.009 & 0.07 & 0.18 \\
\hline E3/3 & 0.7 & 0.79 & 0.74 & 0.63 \\
\hline $\mathrm{E} 4 / 3$ & 0.22 & 0.095 & 0.17 & 0.19 \\
\hline E $4 / 4$ & 0 & 0 & 0 & 0 \\
\hline $\mathrm{E} 4 / 2$ & 0 & 0.009 & 0.004 & 0 \\
\hline \multicolumn{5}{|l|}{ Allelic (gene) } \\
\hline e2 & 0.05 & 0.06 & 0.04 & 0.09 \\
\hline e3 & 0.84 & 0.88 & 0.86 & 0.79 \\
\hline e4 & 0.11 & 0.05 & 0.1 & 0.12 \\
\hline
\end{tabular}

In regard to the association between blood pressure and the ApoE genotypes, some studies have shown an association between systolic blood pressure and the E4E4 and E3E4 genotypes, suggesting that ApoE polymorphism can be a silent factor influencing the increase in blood pressure ${ }^{31}$. Other studies, however, did not show this association ${ }^{32,34}$. In our study, an inverse association was observed: high diastolic blood pressure in the E3E3 elderly; however, no reference was found about this possible association in the literature. This suggests that a correlation between blood pressure levels and ApoE polymorphism may exist, even though no causal genotype-phenotype relation was observed in regard to blood pressure, indicating that other not yet identified genetic-environmental interactions may exist.

It is worth noting that the Finish study on longevity showed a higher mortality in the group of individuals with low blood pressure (both systolic and diastolic) than that in the group of individuals with higher-than-expected blood pressure ${ }^{35}$. This result was later confirmed in similar studies, including the Framingham Study, in which the participants were divided into 2 groups ( $<75$ and $\geq 75$ years). A substantial increase in the mortality rate was observed both in males and females with systolic blood pressure $<120 \mathrm{mmHg}$. As we do not yet know precisely which role hypertension plays in the elderly, and the results here obtained showed an association between high diastolic blood pressure and the E3E3 genotype, we cannot consider that the relation represents an additional risk in the individuals with the referred genotype. Future studies on mortality follow-up in the elderly with different genotypes may clarify whether this relation is beneficial, neutral, or bad.

Analysis of the lifestyle components, such as physical activity, alcohol consumption, and tobacco use, was similar in both groups of genotyped individuals, therefore, eliminating the effect of these variables in the results found. However, additional studies relating the nutritional profile and behavior could eliminate the possibility that this variable would positively influence the maintenance of E3E4 individuals in the population by these individuals adopting a healthy diet.

As the metabolic relation of ApoE polymorphism is directly related to the lipid profile and some types of dyslipidemia that lead to the development of atherosclerosis, a deeper analysis of the association between the lipid profile and ApoE genotypes was performed. ApoE was first reported by Shore and Shore ${ }^{7}$ as a VLDL component, and, therefore, the interest of the initial studies was centered on the attempt to understand the role played by this apolipoprotein in the prevalence of cholesterol-induced hyperlipidemia ${ }^{6,7}$. The subsequent recognition that $\mathrm{ApoE}$ is a protein that binds to the LDL receptor (binding-protein) and that this binding affinity depends on genetically determined isofor$\mathrm{ms}$ accelerated the interest of the specialists in elucidating both ApoE form and function. These studies ended up helping in the understanding of the endogenous and exogenous cholesterol pathways and leading to the association of the ApoE genotypes and alleles with chronic and dege- 
nerative diseases, such as cardiovascular diseases and dementia ${ }^{4,6}$. Throughout these years of investigation of the metabolic role played by ApoE, a large number of articles has been published, but the subject is far from being fully clarified ${ }^{4}$.

In regard to lipid profile, the results obtained in this study showed an association between higher levels of LDL-c and the E3E4 genotype, both in the analyses of the means and in the analysis of the percentiles of the LDL-c levels. The other components did not vary significantly between the groups of different genotypes. The serum lipid levels observed in the different most frequent ApoE genotypes obtained in this study were compared with those recently published in the literature (tab. VIII). It is worth noting that the LDL-c level observed in the elderly of Veranópolis with the E3E4 genotype (155.6 \pm 47.3 ) was very similar to that reported by Bader ${ }^{33}$ for the elderly living in Italy (151.4 \pm 45.5$)$. This suggests that those of the same ethnicity may have similar mean serum lipid levels despite living in different and geographically isolated environmental conditions, ie, a genetic pattern with a reduced environmental influence or maintenance of similar life habits and styles in the 2 populations, or both, despite the migratory event. This statement can be confirmed if we consider the results obtained in the multiethnic study carried out by Pablos-Mendez et $\mathrm{al}^{36}$, which analyzed 1,068 noninstitutionalized individuals living in the United States. The study showed that the association between serum LDL-c levels and those of other lipid components varied according to the ethnic group.

Unlike LDL-c, no correlation was observed between the ApoE genotypes and HDL-c, mainly in regard to the presence of the $\mathrm{E} 4$ allele. This finding was also reported in other population studies, such as that by Pablos-Mendez et al ${ }^{36}$.

Population studies have suggested the association between an increase in the frequency of hypertriglyceridemia (type IV HLP) in individuals with the E2 allele and individuals with the E4E4 genotype; a lower frequency of the E2 allele associated with dyslipidemia IIa; and an increase in the frequency of type IIb dyslipidemia in individuals with at least $1 \mathrm{E} 4$ allele in their genotype ${ }^{32}$. However, the association of the effect of hypocholesterolemia and the E2 allele was stronger than the association of hypercholesterolemia and the E4 allele $^{32}$.

In the third phase of the analysis of the results, the association between the ApoE genotypes with morbidity and other plasma factors of cardiovascular diseases were investigated.

The general analysis of the results showed no association between individuals with the $\mathrm{E} 4$ allele and the morbidity and comorbidity associated with cardiovascular diseases, except the occurrence of a significantly higher number of obese individuals with the E3E3 genotype.

The lack of association with cardiovascular morbidity is not surprising, because data in the literature are controversial. The studies in which a relation between cardiovascular diseases and ApoE genotypes was found report an

\begin{tabular}{|c|c|c|c|}
\hline \multicolumn{4}{|c|}{$\begin{array}{l}\text { Table VIII - Comparison of the lipoprotein parameters and ApoE } \\
\text { genotypes }\end{array}$} \\
\hline & & Veranópolis & Italians ${ }^{32}$ \\
\hline \multirow{4}{*}{$\begin{array}{l}\text { Total cholesterol } \\
(\mathrm{mg} / \mathrm{dl})\end{array}$} & E3E3 & $204.99 \pm 39.28$ & $217 \pm 43.4$ \\
\hline & E3E4 & $224.91 \pm 55.32$ & $229 \pm 48.2$ \\
\hline & E2E3 & $185.15 \pm 77.14$ & \\
\hline & E2E2 & 147.7 & $212 \pm 43.1$ \\
\hline \multirow{4}{*}{$\begin{array}{l}\text { LDL-c } \\
(\mathrm{mg} / \mathrm{dl})\end{array}$} & E3E3 & $133.02 \pm 32.8$ & $142.1 \pm 37.3$ \\
\hline & E3E4 & $155.56 \pm 47.26$ & $151.4 \pm 45.5$ \\
\hline & E2E3 & $109.2 \pm 77.22$ & \\
\hline & E2E2 & 80.37 & $138.3 \pm 39.7$ \\
\hline \multirow{4}{*}{$\begin{array}{l}\text { HDL-c } \\
(\mathrm{mg} / \mathrm{dl})\end{array}$} & E3E3 & $46.7 \pm 12.72$ & $48.5 \pm 9.3$ \\
\hline & E3E4 & $44.8 \pm 10.43$ & $49.3 \pm 12.7$ \\
\hline & E2E3 & $49.96 \pm 5.04$ & \\
\hline & E2E2 & 47.36 & $46.3 \pm 7.5$ \\
\hline \multirow{4}{*}{$\begin{array}{l}\text { Total cholesterol } \\
(\mathrm{mg} / \mathrm{dl})\end{array}$} & E3E3 & $204.99 \pm 39.28$ & $217 \pm 43.4$ \\
\hline & E3E4 & $122.64 \pm 49.57$ & $120.1 \pm 48.7$ \\
\hline & E2E3 & $129.83 \pm 76.4$ & \\
\hline & E2E2 & 100 & $123.5 \pm 49.8$ \\
\hline \multirow{4}{*}{$\begin{array}{l}\mathrm{Lp}(\mathrm{a}) \\
(\mathrm{mg} / \mathrm{dl})\end{array}$} & E3E3 & $30.26 \pm 27.86$ & $25.9 \pm 26.1$ \\
\hline & E3E4 & $29.15 \pm 28.32$ & $30 \pm 35.4$ \\
\hline & E2E3 & $26.73 \pm 20.8$ & \\
\hline & E2E2 & 8.8 & $20 \pm 15$ \\
\hline
\end{tabular}

association between the E3E4 genotype and acute myocardial infarction at an early age ${ }^{31}$. An association between the E4 allele and myocardial ischemia was also observed ${ }^{34}$.

Among the studies in which no consistent association between the ApoE genotypes and cardiovascular diseases was found, we can cite longitudinal studies on the relation between the genotypes and coronary lesions lasting 4 to 6 years ${ }^{37}$. In 1 study carried out in Italy with 15,000 individuals, no association between cardiovascular diseases and differential ApoE genotypes was found ${ }^{33}$. It is still early to confirm or deny the association between the ApoE gene and cardiovascular diseases, because the relation between ApoE and cardiovascular diseases is still controversial. We can infer that if this relation exists, it is not causal (direct) and may be associated with other factors, both genetic and environmental ${ }^{1-4}$.

Other findings of our study that were not reported in studies published about the subject were the relation between high fibrinogen levels and the E3E4 genotype and the relation between more elevated levels of uric acid and the E3E3 genotype. In regard to the former, it is worth noting that elevated fibrinogen levels are associated with cardiovascular diseases ${ }^{22}$. However, despite the differences observed between the 2 genotypes, the fibrinogen levels observed are within the reference levels $(<400 \mathrm{mg} / \mathrm{dL})$ for both groups. Only 1 individual in the entire sample had fibrinogen levels higher than $400 \mathrm{mg} / \mathrm{dL}$. In regard to the second finding, considering that high uric acid levels may increase the risk of cardiovascular diseases ${ }^{38}$, this association could reduce the benefits related to the $\mathrm{E} 3 \mathrm{E} 3$ genotype in regard to atherogenesis.

Our results suggest the hypothesis that we need to increase knowledge about the elderly with longevity, because data in the literature show that the elderly have a biology and a set of risk factors for cardiovascular diseases diffe- 
rent from those of younger individuals. Considering that the prevalence of cardiovascular diseases is very high in individuals with longevity, and that the proportion of these people will significantly increase in the next decades, future studies determining a pattern of cardiovascular risk for this age group will be paramount, both for preventing and handling these risks. Therefore, studies on the polymorphism of genes associated with cardiovascular diseases should be carried out comparing populations of individuals with heart disease with populations of healthy individuals and also individuals above the age of 80 years.

Our results allow us to conclude that, even though no individual with the E4E4 genotype existed in the population studied, suggesting a frequency-dependent effect, no association with risk factors and morbidity related to cardiovascular diseases in heterozygous individuals was observed. This happened even with LDL-c levels significantly hi- gher than those in E3E3 individuals, suggesting the influence of additional environmental factors that were not analyzed in the study (such as nutritional condition) or the interaction with other genetic factors that could reduce or neutralize the negative effects caused by the $\mathrm{E} 4$ allele or reduce the beneficial effects of the E3E3 genotype (such as high uric acid levels). Complementary studies on the relation to other genetic polymorphisms in this population may help to elucidate this hypothesis.

\section{Acknowledgement}

We thank the Coordenação de Aperfeiçoamento de Pessoal (CAPES), Conselho Nacional de Desenvolvimento Científico e Tecnológico (CNPq), Fundação de Amparo à Pesquisa do Estado do Rio Grande do Sul (FAPERGS), and the Municipal Authority of Veranópolis-RS for their support.

\section{References}

1. Mahley RW. Apoliprotein E: cholesterol transport protein with expanding role in cell biology. Science 1988; 240: 622-30.

2. Curtiss LL. ApoE in Atheroslerosis; a protein with multiple hats. Arterioscler Thromb Vasc Biol 2000; 20: 1852-3.

3. Rall SC, Mahley RW. The role of Apoliprotein E genetic variants in lipoprotein disorders. J Intern Med 1992; 231: 653-9.

4. Mahley RW, Huang Y. Apoliprotein E: from atherosclerosis to Alzheimer's disease and beyond. Current Opin Lipid 1999; 10: 207-17.

5. Marian AJ. Genetic risk factors for myocardial infarction. Current Opin Cardiol 1998; 13: 171-8.

6. Mansur AP. Análise do componente genético da doença coronariana. Arq Bras Cardiol 2000; 74: 531-3.

7. Shore VG, Shore B. Heterogeneity of human plasma very low density lipoproteins: separation of species differing in protein components. Biochem 1973; 12: 502-7.

8. Ginsberg HN. Lipoprotein physiology. In: Endocrinology and Metabolism Clinics of North America (lipid disorders). WB Saunders Co., 1998; 27: 503-19.

9. Davignon J, Genest J. Genetic of lipoprotein disorders. In: Endocrinology and Metabolism Clinics of North America (lipid disorders). WB Saunders Co., 1998; 27: 521-50.

10. Davignon J, Gregg RE, Sing CF. Apoliprotein E polymorphism and atherosclerosis. Arteriosclerosis 1988; 8: 1-21.

11. Menzel HJ, Kladetzky RG, Asmann G. Apoliprotein E polymorphism and coronary artery disease. Arteriosclerosis 1983; 3:310-5.

12. Vaupel JW. Biodemographic trajectories of longevity. Science 1998; 55: 1567-9.

13. Christensen K, Vaupel JW. Determinants of longevity: genetic, environmental and medical factors. J Intern Med 1996; 240: 333-41.

14. Robine JM, Forette B, Franceschi C, Allard M. The Paradoxes of Longevity. Berlin: Springer-Verlag, 1999: 73-80.

15. Epidemiologia Y Prevencion De Las Enfermedades Cardiovasculares en Los Ancianos. Organizacion Mundial de la Salud. Informe de un Grupo de Estudio da OMS 1995; 853: 1-12.

16. Núcleo de Informação em Saúde da Secretaria de Saúde e do Meio Ambiente do Estado do Rio Grande do Sul. Estatísticas da Saúde, 1997: 102p.

17. Pereira MG. Epidemiologia. Teoria e Prática. Rio de Janeiro: GuanabaraKoogan, 2000; 269-88.

18. Debomoy KL, Nurnberger Jr JI. A rapid non-enzymatic method for the preparation of HMW DNA from blood for RFLP studies. Nucleic Acid Research 1991; 19: 5444.

19. James E, Hixson JE, VernierDT. Restriction isotyping of human apoliprotein E by gene amplification and cleavage with HhaI. J Lipid Res 1990; 31: 545-8.
20. Tonks DB. Quality control in Clinical Laboratories, Warner-Chilcott Laboratories, Diagnostic Reagent Division, Scarborough, Canadá, 1972: 356p.

21. II Consenso Brasileiro sobre Dislipidemia. Arq Bras Cardiol 1996; 67: 1-16.

22. Pires AJ. Fibrinogênio, Fator VII e Fatores de Risco Cardiovascular em Idosos Acima de 80 anos de Idade. Porto Alegre: Pontifícia Universidade do Rio Grande do Sul, 1996; 1-97.

23. Almeida MSC. Avaliação dos critérios de obesidade em idosos com mais de 80 anos: relação com fatores de risco coronariano. Tese de Mestrado. PUCRS. Porto Alegre, RS, 1997: 123p.

24. III Consenso Brasileiro de Hipertensão Arterial. Campos do Jordão, SP: BTHA, 1998: 38p.

25. Siegel D, Lonergan ET. Hypertension. In: Geriatrics. Connecticut: Appleton \& Lange, 1996: 98-106.

26. Report of the Expert Committtee on the Diagnosis and Classification of Diabetes Mellitus. Diabetes Care 1997; 20: 1183-97.

27. Costa AR. Caracterização da distribuição da HDL e suas subclasses em idosos (dissertação). Porto Alegre (RS): PUCRS, 1996.

28. Silva MJPC. Influência da atividade física sobre os níveis plasmáticos dos lipídeos e lipoproteínas em coronariopatias. Arq Bras Cardiol 1988; 50: 231-6.

29. SPSS. SPSS version 9.0. Chicago, Illinois: SPSS Inc.; 1998.

30. Gardner S. Genética de populações e evolução. In: Genética. $7^{\mathrm{a}}$ ed. Rio de Janeiro: Interamericana; 403-34

31. Siest G, Pillot T, Régis-Bailly A, et al. Apoliprotein E: an important gene and protein to follow in laboratory medicine. Clin Chem 1995; 41: 1068-86.

32. Gabelli C, Martini S, Barbato GM, et al. Apoliprotein E polymorphism and coronoray artery disease. Arteriosclerosis 1983;3:310-5.

33. Bader G, Ziuliane G, Kosner GM, et al. Apoliprotein E polymorphism is not associated with longevity or disability in a sample of italian octo-and nonagenarians. Gerontology 1998; 44: 293-9.

34. Katzel L, Fleg JL, Paidi M, et al. APOE polymorphism increases the risk for exercice-induced silent myocardical ischemia in older men. Aterioscler Thromb 1993; 13: 1495-500.

35. Mattila K, Haaviston M, Tajala S, Heikinheimio R. Blood pressure and five year survival in the very old. Br Med J 1988; 296: 887-9.

36. MendezP, Mayux R, Ngai C, et al. Association of ApoE polymorphism with plasma lipids levels in a multicentric elderly population. Ateriosc Thromb Vasc Biol 1997; 17: 3234-41

37. Phillips NR, Water D, Havel RJ. Plasma lipoproteins and progression of coronary artery disease evaluated by angiography and clinical events. Circulation 1993; 88: 2762-70.

38. Fang J, Alderman MH. Serum uric acid and cardiovascular mortality - the NHANES I epidemiologic follow-up study, 1971-1992. JAMA 2000; 283: 2404-10. 